\title{
CAEP Research Grants
}

\section{What?}

Thanks to an unrestricted grant from Hoffmann-La Roche of Canada, CAEP is once again able to offer EM research grants totalling $\$ 25000$. A working group of the Research Committee will review grant proposals and allocate funds on the basis of originality, methodological quality and relevance to emergency medicine.

\section{Why?}

To promote and support Canadian EM research, especially among junior researchers. Consideration will be given to applications from diverse settings. Academic, non-academic, community and rural emergency physicians are encouraged to apply.

\section{Who?}

CAEP members with less than 6 years of clinical experience will be considered. Applications from nonCAEP members will not be considered. A CAEP member, who will ultimately be responsible for project completion, must supervise resident and student projects. The resident or student should be listed as the Principal Investigator. Previous recipients will not be permitted to hold a second grant until the final report from the previous grant is received at the CAEP office.

\section{When?}

Research proposals must be delivered to the CAEP Head Office no later than 5:00 pm (EST) on Monday, October 18, 2004. Fax and email versions of proposals will not be accepted. The grants will be reviewed, and all applicants will be notified by December 17, 2004.

\section{How?}

Application process: Proposals must be no more than 5 pages of single-spaced text, excluding references and appendices. Size 12 font and unadjusted margins are mandatory. The proposal should be formatted under the following headings: 1) Structured Research Abstract (1 page); 2) Introduction, Rationale, Research Question, and Methods (limit: 3 pages); 3) Timing, Future Plans, and References (limit: 20 references). The research data collection tool and curriculum vitae of the principal investigator must be appended. Proposals that fail to comply with these rules will not be reviewed.

Topics: Applications will be considered from all areas of interest to emergency medicine. Proposals may involve practice audits, feasibility studies, meta-analyses, or small clinical projects. Budget: There are up to 5 grants awarded each year; and maximum per-grant funding is $\$ 5000$. Projects budgeted in excess of this amount will not be considered unless proof of alternative funding is provided. A single page outlining the proposed use of the grant funds is mandatory. No funding will be provided for meetings, conference travel or major purchases (e.g., computers).

Expectations: Successful applicants must provide a final report on the research project and are encouraged to present their completed projects at the CAEP Annual Scientific Meeting.

For further information, please contact Eric Grafstein at egrafstein@ providencehealth.bc.ca 